Bulletin d'Histoire Contemporaine de l'Espagne

$51 \mid 2017$

Les forces politiques durant la Seconde République espagnole

\title{
La gran escisión republicana: azañismo y lerrouxismo
}

The great republican split: azañism and lerrouxism

La grande scission républicaine : azañisme et lerrouxisme

Juan Avilés Farré

(2) OpenEdition

Journals

Edición electrónica

URL: http://journals.openedition.org/bhce/632

DOI: $10.4000 /$ bhce. 632

ISSN: 1968-3723

Editor

Presses Universitaires de Provence

Edición impresa

Fecha de publicación: 1 junio 2017

Paginación: 11-24

ISSN: 0987-4135

Referencia electrónica

Juan Avilés Farré, «La gran escisión republicana: azañismo y lerrouxismo », Bulletin d'Histoire

Contemporaine de l'Espagne [En línea], 51 | 2017, Publicado el 09 octubre 2018, consultado el 05 mayo

2019. URL : http://journals.openedition.org/bhce/632 ; DOI : 10.4000/bhce.632 


\section{La gran escisión republicana: azañismo y lerrouxismo}

\section{JUan AVILÉS FARRÉ}

UNED

$\mathrm{E}$ n las Cortes Constituyentes, elegidas el 28 de junio de 1931 en medio del desconcierto de unas derechas que habían presenciado el repentino hundimiento de la monarquía, los republicanos de vieja tradición sumaban cerca de 250 escaños, es decir algo más de la mitad. El Partido Socialista, que constituía el ala izquierda de la coalición que habia fundado la República, contaba con 115, mientras que el ala derecha de la misma, integrada por los seguidores del jefe de gobierno, Niceto Alcalá Zamora, apenas superaba la veintena ${ }^{1}$. Esto significaba que las Cortes se escoraban mucho a la izquierda respecto a la realidad social, como se comprobaría por los resultados de las derechas en las elecciones de 1933 y 1936, pero daba opción a tres mayorías gubernamentales diferentes: una que mantuviera la amplia coalición de abril, otra exclusivamente republicana, sin el PSOE, y otra integrada por la izquierda republicana y los socialistas, como la que efectivamente se formó bajo la presidencia de Manuel Azaña.

Esa opción, que dividió a los republicanos entre los afines a Azaña y los afines a Alejandro Lerroux, no resultaba sin embargo la más obvia en aquel verano de 1931. Por el contrario, tanto los casi cien diputados del Partido Radical de Lerroux como los casi treinta del partido de Azaña, Acción Republicana, formaban parte de una Alianza Republicana fundada en 1926 que habia tomado la iniciativa de unir a las fuerzas dispersas que se integrarian en el Pacto de San Sabastián de 1930 y lograrian el triunfo republicano de $1931^{2}$. El 10 de julio, recién elegidas las Cortes Constituyentes, se reunió el Consejo Nacional de la Alianza y se acordó por unanimidad formar un bloque parlamentario, después de que a Azaña se le garantizaran dos cuestiones que le importaban mucho: la libertad de organización y propaganda de los partidos que integraban esta Alianza y el mantenimiento del carácter izquierdista de ésta ${ }^{3}$. Aún más a su izquierda se situaba el Partido Republicano Radical Socialista, encabezado por Marcelino Domingo y Álvaro de Albornoz, que se habia mantenido al margen de la Alianza.

1 Julio Gil Pecharroman, Historia de la Segunda República Española, Madrid, Biblioteca Nueva, 2002, p. 58 .

2 Sobre el Partido Radical, la obra pionera es la de Octavio Ruiz Manjón, El Partido Republicano Radical, Madrid, Tebas, 1976, y la más completa es la de Nigel Townson, La República que no pudo ser, Madrid, Taurus, 2002. Sobre los partidos de Azaña véase, Juan Avilès, La izquierda burguesa y la tragedia de la II República, Comunidad de Madrid, 2006. Sobre la trayectoria inicial de Lerroux, José Álvarez Junco, El emperador del Paralelo, Madrid, Alianza Editorial, 1990. La mejor biografia de Azaña es la de Santos Julı̇, Vida y tiempo de Manuel Azaña, Madrid, Taurus, 2008. Añádase, Leandro Álvarez Rey, Diego Martinez Barrio: palabra de republicano, Ayuntamiento de Sevilla, 2007.

3 Ahora, 11-7-1931 y 14-7-1931. Manuel Azaña, Obras Completas, Madrid, Centro de Estudios Politicos y Constitucionales, 2008, v. III, p. 611-612- 
La gran mayoría de los diputados de Acción Republicana habían sido elegidos en candidaturas de las que formaban parte también los radicales y, aunque la disciplina de voto en aquellas Cortes era más bien escasa, votaron a menudo con ellos en los debates constitucionales, mientras que los radicales socialistas solían optar por posiciones más izquierdistas, a menudo en coincidencia con el $\mathrm{PSOE}^{4}$. Ello ocurrió, por ejemplo, cuando a comienzos de octubre se debatió la cuestión de la propiedad y los diputados de Acción Republicana se unieron a los radicales para enmendar la propuesta socialista que anunciaba una socialización gradual de la propiedad, sin indemnización en los casos en que la necesidad social lo exigiera, propuesta que tuvo en cambio el apoyo de los radicales socialistas ${ }^{5}$. De hecho, ya en julio Albornoz había declarado que, cuando el Gobierno provisional hubiera concluido su tarea, debería gobernar el PSOE con el apoyo del Partido Radical Socialista y de la Esquerra Catalana ${ }^{6}$. Sin embargo, existían también divisiones internas entre los radicales socialistas, cuyo otro líder más destacado, Domingo, le comentó a Azaña que Albornoz estaba loco y que sus compañeros de partido jugaban a las revoluciones. Azaña anotó en su diario que con los radicales socialistas no podría entenderse, no por diferencia de ideas, pues todos los republicanos pensaban lo mismo, sino por disparidad de temperamentos, porque aquel partido estaba lleno de «gentes díscolas y arrebatadas»?

Sin embargo, Azaña terminaría por ligar su suerte a la de socialistas y radicales socialistas. En octubre, cuando Alcalá Zamora dimitió tras la aprobación de las cláusulas anticlericales de la Constitución, fue Azaña quien formó un gobierno de coalición republicano-socialista, amputado sólo del sector más conservador del republicanismo, y en diciembre los radicales aprovecharon la crisis de gobierno que se produjo tras la elección de Alcalá Zamora como presidente de la República para pasar a la oposición. Durante casi dos años Azaña llevaría pues a cabo una difícil política de reforma profunda del Estado y de la sociedad españolas, basándose en el apoyo del PSOE, que abogaba por una política de socialización contraria a los principios del republicanismo y cuya política a nivel local le enfrentó a las clases medias, y de los diputados «díscolos y arrebatados» del Partido Radical Socialista, parte de los cuales se sumarían en 1933 a la marea de críticas contra el PSOE y a favor de un cambio de gobierno.

¿Cómo se llegó a esa situación? Hubo varios factores importantes. En primer lugar, el PSOE no deseaba asumir la presidencia del gobierno hasta que estuviera en condiciones de aplicar su propio programa, pero quería impulsar una política gubernamental de izquierda. En segundo lugar, una parte importante de los diputados republicanos, carentes por completo de experiencia gubernamental, se sentían más atraídos por la perspectiva de una ruptura radical con la tradición española, como la propugnada por Azaña, que por el intento de consolidar la democracia republicana mediante una política de atracción hacia los sectores conservadores, como la que proponía Lerroux. Y además este último, a diferencia de Azaña, demostró en aquellos meses decisivos una notoria falta de liderazgo. Él era el líder por excelencia del republicanismo histórico y el jefe indiscutido del partido republicano con mayor representación parlamentaria, pero no sólo había permitido que la

4 Sobre las coaliciones electorales de ambos partidos véase AvmÉs, La izquierda..., p. 103. Sobre el Partido Radical Socialista véase también Manuel Álvarez TARDio, «La democracia de los radicalsocialistas), en Fernando DEL REY, ed., Palabras como puños: la intransigencia política en la Segunda República española, Madrid, Tecnos, 2011.

5 AvLÉs, La izquierda..., p. 130-131.

6 El Sol, 18-7-1931.

7 AzañA, Obras..., v. III p. 686 y 697. 
desconfianza de sus compañeros del gobierno provisional le relegara a la posición poco relevante de ministro de Asuntos exteriores, sino que aprovechó esa posición para acudir siempre que pudo a los debates de la Sociedad de Naciones en Ginebra, donde no brilló por su conocimiento de los asuntos internacionales. Su voz tampoco se oyó en las Cortes cuando estaba en Madrid, así es que no jugó papel alguno en los decisivos debates constitucionales en los que se jugaba la orientación de la naciente democracia republicana. En palabras de su colaborador Diego Martínez Barrio, Lerroux había asumido el papel de «gran ausente» ${ }^{8}$.

En esas condiciones, quedaba en el aire su autoproclamado papel de integrador de los sectores conservadores en una República «para todos los españoles», tal como había proclamado en la campaña electoral ${ }^{9}$. Al no haber intentado evitar que se aprobaran los artículos más polémicos de la Constitución, especialmente el 26, de fuerte contenido anticlerical, se había situado en una situación difícil para cuando tuviera la ocasión de aplicar su proyecto de centrar a la República. Cierto es que Lerroux no debía suponer por entonces que su futuro gobierno iba a depender de una derecha católica con fuerte representación parlamentaria. Su estrategia en diciembre de 1931 parece haber sido la de esperar a que la coalición de izquierdas presidida por Azaña fracasara, para recibir a continuación del presidente de la República el encargo de formar un gobierno que presidiera la celebración de nuevas elecciones. No se olvide que, en la tradición española, el gobierno que organizaba unas elecciones siempre las ganaba. Sin embargo, a principios de septiembre, Alcalá Zamora había asegurado a Azaña que ningún presidente de la República entregaría a un gobierno presidido por Lerroux el decreto de disolución de las Cortes Constituyentes, «porque volver a las mayorías homogéneas, sacadas a la fuerza, sería destruir la República ${ }^{10}$.

La desconfianza del presidente Alcalá Zamora se convertiría, en 1934 y 1935, en un serio obstáculo para los planes de Lerroux, pero las relaciones de aquél con Azaña, en 1932 y 1933, fueron también difíciles. En realidad, en sus esfuerzos por evitar que la República se escorara demasiado hacia la izquierda o hacia la derecha, Alcalá Zamora tendió a excederse en sus intervenciones presidenciales. Cuando en junio de 1933 aprovechó que Azaña le planteara una remodelación de su gobierno para forzar su dimisión, éste lo consideró una «atrocidad», porque consideraba que en un régimen parlamentario el presidente de la República sólo podía retirar su confianza a un gobierno en el caso de que éste hubiera perdido unas elecciones o recibido un voto desfavorable de las Cortes ${ }^{11}$.

No le faltaba razón, pero lo cierto es que para entonces la posición política de Azaña era mucho más endeble de lo que él parecía suponer. Sus dos años de gobierno habían sido, por diversos motivos, muy difíciles. La política laboral de los socialistas, con el líder de la UGT Francisco Largo Caballero en el ministerio de Trabajo, exasperó a los propietarios grandes y pequeños y no contribuyó para nada a reducir la hostilidad hacia la República de la CNT, que se negó a aceptar el marco de relaciones laborales diseñado por sus rivales de la UGT. En julio de 1933, un sector del propio Partido Radical Socialista, encabezado por Félix Gordón Ordax, exigió a Azaña una revisión de la política laboral impulsada por Caballero, que en su opinión implicaba un ataque a la libertad de trabajo en beneficio de los afiliados

8 Diego Martínez Barrio, Memorias, Barcelona, Planeta, 1983, p. 58. Townson, La República..., p. 115-116.

9 Sobre el papel integrador asumido por Lerroux, véase Townson, La República ..., p. 53-55.

10 AZAÑa, Obras..., v. III, p. 711.

11 Azaña, Obras..., v. IV, p. 748 y 753. 
a la UGT ${ }^{12}$. La aprobación del Estatuto de Cataluña satisfizo viejas aspiraciones catalanas, pero irritó a los sectores que veían en ello una concesión al separatismo, y aunque Azaña fue un firme impulsor del mismo, no faltaban incluso en su partido los diputados hostiles al estatuto, hasta el punto de que en el verano de 1932 su aprobación en las Cortes pareció peligrar, aunque fue finalmente votado tras el fracaso de la intentona golpista del general Sanjurjo $^{13}$. La ley de Confesiones y congregaciones religiosas de 1933, que implicaba la prohibición de los centros de enseñanza regidos por las órdenes religiosas, presentada por el diputado radical socialista Fernando Valera como un «ley de paz», no lo fue en absoluto y dio mayor fuerza a la movilización de la derecha católica ${ }^{14}$. Y en fin, la política de orden público se vio dificultada por protestas violentas de los trabajadores, a veces impulsadas por los socialistas, frente a las cuales la respuesta de las fuerzas del orden fue a menudo brutal y letal. Lo más grave fueron las sucesivas insurrecciones promovidas por la CNT, una de las cuales, la de enero de 1933, dio lugar a la matanza de Casas Viejas, en la que una docena de campesinos detenidos fueron asesinados a sangre fría por un grupo de guardias de asalto, lo que a su vez se convirtió en un escándalo que explotaron a fondo contra Azaña todos los enemigos del gobierno, incluidos los radicales ${ }^{15}$.

El propio Azaña concebía inicialmente la colaboración con el PSOE como una etapa temporal, necesaria para el afianzamiento de la República, que más tarde había de dar paso a gobiernos exclusivamente republicanos. En el verano de 1931 había anotado en su diario que, dado el estado de «guerra civil» existente entre UGT y CNT, sería conveniente que los socialistas se retiraran del gobierno, aunque no veía clara la posibilidad de una coalición alternativa ${ }^{16}$. Sin embargo, tras su ruptura con los radicales, no tardó en otorgar un valor histórico a la incorporación de los socialistas a la República, más allá de su presencia o no en el gobierno. Lo afirmó en un importante discurso pronunciado el 14 de febrero de 1933, en el que concluyó que se trataba de saber si era posible hacer «una transformación profunda de la sociedad española» que le evitara «los horrores de una revolución social» ${ }^{17}$. El problema fue que un sector numeroso del PSOE, encabezado por Caballero, se fue orientando progresivamente hacia la revolución social, sin que Azaña pareciera inquietarse por ello. No se encuentra, por ejemplo, ningún comentario en su diario a un discurso pronunciado por Caballero el 15 de agosto de 1933, cuando todavía era ministro, en el que afirmó estar convencido de que realizar una obra socialista dentro de una «democracia burguesa» era imposible y que después de la República sólo podría venir un régimen socialista, «nuestro régimen» ${ }^{18}$.

El choque entre socialistas y radicales habia comenzado mucho antes, incluso cuando ambos partidos formaban partent del gobierno provisional, pues el 30 de junio de 1931 el ministro socialista Indalecio Prieto había afirmado qu'un gobierno Lerroux no contaría ni con la colaboración, ni con el apoyo, ni con la confianza del PSOE ${ }^{19}$. En el ámbito rural, los choques entre los afiliados radicales de clase media y los jornaleros afiliados a la UGT

12 El Sol, 6 a 9-7-1933. Partido Republicano Radical Socialista, Texto taquigráfico del III Congreso Nacional Extraordinario, p. 143-145 y 197-199.

13 AvLÉs, La izquierda..., p. 196-200.

14 Discurso de Valera en Diario de Sesiones de las Cortes, 18-2-1933.

15 Este asunto ha sido minuciosamente esclarecido por Tano Ramos, El caso Casas Viejas, Barcelona, Tusquets, 2012.

16 AzAÑa, Obras..., v. III, p. 649.

17 AzAÑa, Obras..., v. IV, p. 193-204.

18 El Socialista, 13-8-1933.

19 El Sol, 1-7-1933. 
daban un trasfondo social a la rivalidad política de ambos partidos y algo similar ocurría también en el ámbito urbano ${ }^{20}$. En octubre de 1931, los socialistas ya veían en Lerroux al «caudillo de las derechas», mientras que se presentaban a ellos mismos como «la fuerza única» que impulsaba la revolución ${ }^{21}$. Lerroux, por su partent, calificó a los socialistas de «asesinos de la libertad» en un discurso que pronunció el 10 de julio de 1932, en el que denunció además al gobierno de Azaña por estar provocando unos «actos de rebeldía» que no podrían ser reprimidos sólo por la fuerza, porque se apoyaban «en fundamentos de razón $\rangle^{22}$. Era una forma muy poco disimulada de estimular a quienes estaban preparando un golpe militar y ello nos conduce a la cuestión de la complicidad de Lerroux con la intentona del general Sanjurjo del 10 de agosto de 1932. El análisis de Nigel Townson lleva a la conclusión de que el líder radical estaba al corriente de que el general tramaba un golpe y que probablemente esperaba beneficiarse del mismo, aunque se mantuvo en una posición discreta y optó por ausentarse de Madrid la noche en que se produjo. Sin embargo, sólo un estrecho grupo de colaboradores de Lerroux estaban al tanto y el Partido Radical en su conjunto no estuvo implicado. Martínez Barrio había denunciado las actividades conspirativas y los radicales sevillanos se opusieron activamente al golpe de Sanjurjo en la ciudad andaluza ${ }^{23}$.

El renacimiento de la solidaridad republicana provocado por la intentona de Sanjurjo, que permitió la aprobación del Estatuto de Cataluña y de la reforma agraria, fue sin embargo de escasa duración. La matanza de Casas Viejas, en enero de 1933, proporcionó a los radicales la coartada necesaria para lanzarse a una oposición implacable contra el gobierno de Azaña. En un discurso que parecía justificar en parte el recurso a las armas por parte de los extremistas de derecha e izquierda, Lerroux afirmó en las Cortes que así como el fracaso político del gobierno había culminado en el intento de golpe de Estado de agosto, su fracaso social había dado lugar al levantamiento de la $\mathrm{CNT}^{24}$. Durante varios meses los radicales y otros grupos de la oposición obstruyeron la labor del gobierno mediante la presentación de centenares de enmiendas a sus proyectos, que quedaban así paralizados a no ser que el gobierno recurriera a la drástica medida de hacer votar el final del debate, lo que se conocía como «guillotina». Los radicales apoyaron, sin embargo, la aprobación en mayo de la anticlerical ley de congregaciones ${ }^{25}$.

La posición política del gobierno se veía además amenazada por el crecimiento en el seno del Partido Radical Socialista de una corriente contraria a la colaboración con los socialistas. Los síntomas de que el gobierno había perdido el apoyo de una buena parte de la opinión pública se multiplicaban, y en junio de 1933, Alcalá Zamora forzó la dimisión de Azaña, a quien sin embargo tuvo que encargar de nuevo que formara gobierno, tras haber comprobado la imposibilidad de una mayoría alternativa en aquellas Cortes. Fue sin embargo una prorroga puramente temporal, pues, el 7 de septiembre, el presidente de la República retiró su confianza a Azaña y que, el 15 de septiembre, Lerroux logró finalmente formar su primer gobierno, fue de concentración republicana y en el que el partido de

20 Townson, La República..., p. 108-109 y 137-151.

21 El Socialista, 25-10-1931.

22 El Sol, 12-7-1932.

23 Townson, La República..., p. 168-179.

24 Diario de Sesiones de las Cortes, 3-2-1933.

25 Townson, La República ..., p. 190-203. Avilés, La izquierda ..., p. 239-246. 
Azaña estuvo representado por un ministro, no sin que ello creara disgusto en su seno. Por su parte, el Partido Radical Socialista se escindió a finales de septiembre ${ }^{26}$.

Lerroux sabía que con aquellas Cortes de orientación izquierdista no iba a poder gobernar, pero a su vez sabía que no era fácil que Alcalá Zamora le diera el decreto de disolución. Se presentó a las Cortes con un discurso muy provocativo, en el que las acusó de estar divorciadas de la opinión (como era cierto, según se demostraría en las elecciones) $\mathrm{y}$, el 3 de octubre, fue derrotado en una moción de desconfianza presentada por Prieto. En aquella difícil situación, Alcalá Zamora encargó formar gobierno a Martínez Barrio, una solución que Lerroux aceptó, aunque luego en sus memorias la descalificaría como una traición. También se avino a aceptar, como le solicitaron Azaña y Domingo, que Martínez Barrio pidiera la incorporación de los socialistas a su gobierno. Parecía pues que era posible reconstruir la coalición que había fundado la República, al menos a efecto de presidir las próximas elecciones, pero fueron los socialistas quienes se negaron a incorporarse al nuevo gobierno, en el que sí estarían representados los partidos de Azaña y Domingo ${ }^{27}$. La coalición republicano-socialista se había roto definitivamente y el PSOE no tardaría en orientarse hacia la ruptura con las instituciones republicanas y la toma revolucionaria del poder. En agosto, Caballero había recordado que en la transición del capitalismo al socialismo era inevitable la dictadura del proletariado y, en septiembre, afirmó que el choque seria inevitablemente violento ${ }^{28}$.

Sin embargo, en aquel mes de julio el gobierno de Azaña había hecho aprobar por las Cortes una ley electoral que pretendía forzar a los partidos a coaligarse, al menos en la segunda vuelta, y para ello establecía que para vencer en la primera una candidatura debía alcanzar al menos el $40 \%$ de los votos, un porcentaje difícilmente alcanzable para un partido aislado. A Alcalá Zamora ello le había parecido un error gravísimo porque, según le explicó a Azaña, iba a forzar a los electores a dividirse en dos bandos y, si tenían que elegir entre los socialistas y las derechas, la mayoría preferiría a estas, mientras que los republicanos se verían obligados a mendigar el apoyo de los unos o de las otras. Eran palabras proféticas, porque escindidos los republicanos en un ala izquierda y un ala derecha incapaces de entenderse, un sistema electoral mayoritario que primaba a las coaliciones les forzaría a depender de aliados incómodos, como lo demostrarían ser tanto la CEDA como los socialistas. En julio de 1933, Azaña parecía creer que la coalición republicanosocialista era sólida, pero unas semanas después de aprobada la ley electoral, se dio cuenta del peligro que se avecinaba. «Los socialistas -escribió en su diario el 26 de agosto- acaban de votar una nueva ley electoral que hemos planteado juntos partiendo del supuesto de la coalición, que nos aseguraría grandes mayorías. Que ahora, vigente esa ley, quieran, como piden ya algunos, romper la coalición, sería un suicidio» ${ }^{29}$.

Aunque no faltaron, en algunas localidades, las coacciones y los incidentes violentos, de los que fueron responsables elementos de todos los partidos, las elecciones generales de 1933 fueron las más honestas que se hubieran celebrado en España hasta entonces. El gobierno de Martínez Barrio intervino en su desarrollo menos que cualquiera de sus predecesores y en especial destacó por su limpieza la gestión del ministro de Gobernación, el independiente

26 AvıÉs, La izquierda.., p. 246-280

27 Townson, La República ..., p. 219-222. AvILÉs, La izquierda ..., p. 287-291.

28 El Socialista, 13-8-1933 y 24-9-1933.

29 AzAÑA, Obras..., v. IV, p. 795 y 827. 
Manuel Rico Avello ${ }^{30}$. En contra de lo supuesto por Azaña, el 80\% de los diputados fueron elegidos en la primera vuelta, que resultó catastrófica para los republicanos de izquierda, excepto en Cataluña. En conjunto, los partidos de derechas ajenos a la coalición fundadora de la República obtuvieron doscientos cincuenta escaños, los republicanos de centro ciento vintisiete, los de la izquierda obrera sesenta y dos y los de la izquierda republicana trenta y tres $^{31}$. De estos últimos, dieciocho correspondieron a los nacionalistas catalanes de Esquerra Republicana, lo que significa que los republicanos de izquierda del resto de España, que en muy pocas circunscripciones lograron coaligarse con los radicales o con los socialistas, sólo obtuvieron quince.

En su conjunto las izquierdas obtuvieron aproximadamente un tercio de los votos, que, debido al carácter mayoritario del sistema electoral, les proporcionaron tan sólo un $20 \%$ de los escaños, y es importante destacar que ello no se debió sólo a la ruptura entre socialistas y republicanos. Si los partidos representados en el gobierno de Azaña hubieran sumado sus votos, sus resultados hubieran sido mejores, pero aun así sólo habrían triunfado en la cuarta parte de las circunscripciones. En cambio la coalición del primer gobierno Azaña, que incluía a los socialistas y los radicales, habría triunfado en dos tercios de ellas, mientras que una coalición republicana lo habría hecho en casi la mitad. Los enfrentamientos del primer bienio habían supuesto, sin embargo, la escisión definitiva del republicanismo y lo que las urnas demostraron en 1933 es que la mayoría de los ciudadanos rechazaba la política de Azaña y los socialistas ${ }^{32}$. En cuanto a la hipótesis de que el voto femenino, que se ejerció por primera vez en 1933, pudo haber resultado decisivo para el triunfo de las derechas, como arguyeron algunos portavoces de las izquierdas, parece que puede descartarse a la luz del estudio más reciente y exhaustivo de estas elecciones ${ }^{33}$.

Los republicanos de izquierda no aceptaron de buen grado el veredicto de las urnas y hay indicios de que pretendieron una inmediata disolución de las Cortes recién elegidas, aunque este punto no ha sido plenamente esclarecido ${ }^{34}$. Lo indudable es que el 5 de diciembre Manuel Azaña, Marcelino Domingo y Santiago Casares Quiroga dirigieron a Martínez Barrio una carta en la que planteaban la urgente necesidad de que se formara un gobierno republicano que diera la seguridad de que el rumbo de la República no iba a «desviarse peligrosamente», una afirmación que sólo puede interpretarse como una exigencia de que no se hicieran concesiones a la mayoría derechista de las nuevas Cortes. Añadían, además, que sólo así podrían evitarse «resoluciones ulteriores», guiadas por «los más altos intereses del país», lo que parecía implicar una velada amenaza a recurrir a medios no constitucionales para evitar que quienes habían ganado las elecciones pudieran imponer una nueva orientación política ${ }^{35}$.

En realidad, los resultados electorales permitieron el regreso de Lerroux a la jefatura del gobierno, pero en condiciones difíciles, porque dependía de la benevolencia parlamentaria de las derechas «accidentalistas» agrupadas en la CEDA, que con ciento quince escaños constituían el grupo parlamentario más numeroso, por delante de los ciento cuatro de los

30 Las elecciones de 1933 han sido objeto d'un análisis minucioso en Roberto VILLA GARcía, La República en las urnas, Madrid, Marcial Pons, 2011.

31 Gil Pecharromán, Historia ..., p. 179.

32 Avilés, La izquierda..., p. 295-303.

33 Villa García, La República..., p. 359-372.

34 La credibilidad de las versiones que Alcalá Zamora y Martínez Barrio dieron de las gestiones realizadas por los líderes de la izquierda republicana ha sido objeto de diversas valoraciones. Véanse AvILÉs, $L a$ izquierda ..., p. 304-307; Juliá, Vida y tiempo ..., p. 345-346; Vll LA Garcí, La República ... p. 439-442.

35 Azaña, Obras..., v. V, p. 664. 
radicales. Entre el centro republicano y la derecha accidentalista había posibilidades de acuerdo respecto a la revisión de algunos aspectos de la política izquierdista del primer bienio, pero las diferencias eran también notables, hasta el punto de que José María Gi1 Robles llegó a escribir en sus memorias que del ideario de Lerroux le apartaba un abismo ${ }^{36}$. Baste recordar que el radical era un partido laico que había votado a favor de la Constitución de 1931, mientras que la CEDA era un partido confesional católico que aborrecía esa Constitución y aspiraba a un nuevo modelo de Estado, nunca bien precisado, pero que parecía alejarse bastante de la democracia parlamentaria que aquella consagraba. En enero de 1934, Gil Robles explicó en una entrevista que, si en el momento apropiado no se le permitía a la CEDA gobernar, tendrían que explicar al pueblo que la vía de la democracia no servía y buscar «otras soluciones», una posición bastante similar a la adoptada por Largo Caballero en el verano de $1933^{37}$.

Lerroux daba además muestras de cansancio y, en palabras de Townson, fue un jefe de gobierno «carente de energía y firmeza» ${ }^{38}$. Estuvo dispuesto a hacer muchas concesiones a la CEDA, pero con ello perdió el apoyo del ala izquierda de su propio partido y del presidente de la República, que estaba decidido a frenar las ambiciones de Gil Robles. El descontento de algunos radicales por la orientación derechista del gobierno Lerroux, visible en temas como la política de orden público, la sustitución de ayuntamientos por motivos políticos, el incumplimiento de la legislación anticlerical y de la legislación laboral, condujo en mayo de 1934 a la escisión de Martínez Barrio y otros veintiún diputados, que en agosto de ese año confluyeron con Gordón Ordax y otros náufragos del radical-socialismo en un nuevo partido que se denominó Unión Republicana, en una muestra de la porosidad de las fronteras entres los dos sectores en que el republicanismo se había dividido en $1931^{39}$.

Previamente se había producido el choque entre Lerroux y Alcalá Zamora, quien manifestó su descontento con la ley de amnistía que puso en libertad a los golpistas de 1932 en una extensa nota en la que manifestó sus objeciones personales y, cuando poco después Lerroux le presentó su dimisión por una cuestión protocolaria, se la aceptó y encargó formar gobierno a otro miembro del Partido Radical, Ricardo Samper. Esto demostró no sólo la voluntad del presidente de la República de controlar al gobierno, sino la falta de cohesión en el Partido Radical y de firmeza en Lerroux, que se dejó marginar. Como ha escrito Townson, al no ser el líder de su partido, Samper careció de autoridad desde el principio, pero su posición se vio ulteriormente debilitada por la escisión de Martínez Barrio, que le privó de un útil contrapeso frente al ala derecha de su partido. Con todo, el gobierno Samper representó un significativo esfuerzo de llevar a cabo una política de centro, visible en su gestión de los conflictos laborales, cuya equidistancia no contentó a la patronal ni a los sindicatos; en sus esfuerzos por satisfacer las demandas de la Federación Nacional de Trabajadores del Campo de la UGT, que no evitó la huelga general agraria de junio; y finalmente en su voluntad negociadora con el gobierno catalán respecto al conflicto surgido en torno a la ley de contratos de cultivo ${ }^{40}$.

El nuevo partido azañista de Izquierda Republicana, surgido en abril de 1934 por la fusión de Acción Republicana con los radicales socialistas de Marcelino Domingo y los republicanos gallegos de Santiago Casares Quiroga, optó sin embargo por una oposición

\footnotetext{
36 José María Gı Robles, No fue posible la paz, Ariel, Barcelona, 1968, p. 164.

37 Renovación, 2-1-1934.

38 Townson, La República..., p. 255.

39 Townson, La República ..., p. 255-258 y 264-272. Avilés, La izquierda ..., p. 326-333.

40 Townson, La República ..., p. 259-261 y 281-302.
} 
radical frente al gobierno de Samper y en su declaración fundacional llamó a una «movilización de la España republicana» que rectificara el rumbo del régimen ${ }^{41}$. Para ello no podrán contar con los socialistas, que habían descartado por completo nuevos acuerdos con los republicanos y optado por la conquista del poder, aunque remitieron su alzamiento al momento en que se produjera una provocación de la derecha ${ }^{42}$. El propio Azaña adoptó un tono revolucionario, y en abril afirmó en un discurso que por encima de la Constitución estaba la República y por encima de la República la Revolución, pero ello no implicaba que se planteara, como los socialistas, una insurrección armada ${ }^{43}$. No excluyó el recurso al presidente de la República y en una reunión que tuvo con Felipe Sánchez Román, Diego Martínez Barrio y Miguel Maura, este último recibió el encargo de plantear a Alcalá Zamora «la posibilidad de rescatar la República mediante un gobierno nacional de defensa republicana». La gestión de Maura, realizada el 5 de junio, no obtuvo sin embargo resultado. Un mes después, el 7 de julio, fue Martínez Barrio quien se entrevistó con el presidente para proponerle, de acuerdo con Azaña y Sánchez Román, la formación de un «gobierno nacional republicano» y en un breve plazo la disolución de las Cortes. Tras rechazar Alcalá Zamora esta propuesta, Martínez Barrio le advirtió que «los republicanos todos» se sentían «fuera de toda solidaridad» con aquella manera de dirigir la República ${ }^{44}$. Esto implicaba que los líderes republicanos de izquierda no consideraban que el gobierno de Samper fuera republicano y que buscaban la salvación de la República en la formación de un gobierno minoritario que en unos meses convocara nuevas elecciones y por supuesto las ganara. Sin embargo, esto último resultaba por lo menos dudoso, dado que los socialistas mostraban nula disposición a renovar la coalición electoral con los republicanos y que la posibilidad de cocinar una victoria en el ministerio de la Gobernación, como era habitual en la monarquía, quizá no fuera ya factible en las condiciones de movilización política de los años treinta. Lo cierto es que el 27 de julio Sánchez Román, Azaña y Martínez Barrio, suscribieron un manifiesto en que declaraban hallarse «fuera de toda solidaridad moral y política» con las conductas y métodos que desfiguraban la República (entiéndase, las del gobierno de Samper y las del presidente de la República, que se había negado a darles el poder a ellos). Este manifiesto no llegó sin embargo a hacerse público, debido a la oposición de Maura ${ }^{45}$.

Poco después de que Alcalá Zamora rechazara las exigencias de Martínez Barrio, Azaña había podido comprobar que la negativa socialista a todo acuerdo era inamovible. Según explicó el propio Azaña en carta a un íntimo amigo, en una reunión celebrada el 14 de julio Caballero le explicó que los socialistas habían acordado «no colaborar con los republicanos ni para la paz ni para la guerra», porque iban a hacer la revolución ellos solos ${ }^{46}$. A aquella reunión entre republicanos y socialistas asistió también Joan Lluhí, consejero de Justicia de la Generalitat catalana, quien agradeció al PSOE su apoyo a la Generalitat en el caso de que

41 Avilés, La izquierda..., p. 320-326.

42 AvilÉs, «Los socialistas y la insurrección de octubre de 1934», Espacio, Tiempo y Forma: Historia Contemporánea, $\mathrm{n}^{\circ} 20,2008$, p. 129-157.

43 Discurso a los jóvenes republicanos, 16-4-1934, en AZAÑa, Obras..., V, p. 98-108.

44 Acta de las reuniones celebradas por Felipe Sánchez Román, Manuel Azaña y Diego Martínez Barrio, 7-7-1934, en Azaña, Obras..., V, p. 150-152. Martínez Barrio, Memorias, p. 232-234 y 246-247.

45 Nota conjunta de Felipe Sánchez Román, Manuel Azaña y Diego Martínez Barrio, 27-7-1934, en Azaña, Obras..., V, p. 153. Martínez Barrio, Memonias, p. 234-237.

46 Carta a Cipriano Rivas Cherif, 23-7-1934, en Azaña, Obras..., V, p. 667-668. 
se le pretendiera arrebatar a Cataluña su autonomía, pero advirtió que la Esquerra no apoyaría un gobierno exclusivamente socialista, como el que Caballero pretendía implantar ${ }^{47}$.

Fracasadas las gestiones con Alcalá Zamora y con Largo Caballero, el único posible aliado que le restaba a Azaña para impulsar un cambio de rumbo era el gobierno de la Generalitat, enfrascado en un grave conflicto institucional por su negativa a aceptar la anulación de la ley catalana de cultivos por el Tribunal de Garantías constitucionales. Ahora bien, Azaña se trasladó aquel verano a Cataluña, para tomar las aguas en un balneario, y regresó de nuevo a fines de septiembre, para asistir al entierro de un colaborador. Así es que se hallaba en Barcelona cuando el 6 de octubre, en respuesta a la entrada de la CEDA en el gobierno, el presidente de la Generalitat, Lluis Companys, proclamó el Estado catalán, iniciando una insurrección que fue aplastada en pocas horas. Qué conversaciones tuvo Azaña con los políticos catalanes y cuál fue el propósito de su permanencia en Barcelona son cuestiones que no se han esclarecido, pero lo cierto es que no apoyó la insurrección nacionalista de Companys, aunque en mi opinión sí habría estado dispuesto a apoyar desde Barcelona un pronunciamiento pacífico encaminado a cambiar el rumbo de la República, traicionada en su opinión por quienes habían dado entrada en el gobierno a la derecha accidentalista ${ }^{48}$. Un propósito de ruptura con la legalidad que había expresado en un discurso pronunciado el 30 de agosto en Barcelona, cuando afirmó que si un día la República se viera «en poder de los monárquicos más o menos disfrazados», no habría justificación constitucional que valiera y «sería hora de pensar que habiendo fracasado el camino del orden y de la razón, habríamos de conquistar a pecho descubierto las garantías que el porvenir no volviera a ponerse tan oscuro $)^{49}$.

Gil Robles, muy descontento con la moderación centrista de Samper, había anunciado en agosto que, de seguir en esa línea, le retiraría su apoyo cuando el 1 de octubre se reabrieran las Cortes. El propio Lerroux consideró correcta esta posición de la CEDA y el ministro de Gobernación Rafael Salazar Alonso, miembro destacado del ala derecha del Partido Radical, consideraba incluso que la entrada del gobierno de la CEDA forzaría a los socialistas a precipitar la revolución que habían anunciado. En el grupo parlamentario radical había disparidad de opiniones respecto a la CEDA, pero la única opción alternativa a la aceptación de sus exigencias era la disolución de las Cortes, algo que ni los radicales ni el propio Alcalá Zamora deseaban. Así es que el 4 de octubre se anunció la formación de un nuevo gobierno de Lerroux, con la participación de tres ministros de la CEDA, pero sin la presencia de Salazar Alonso, a quien Alcalá Zamora era contrario ${ }^{50}$. El resultado fue el pronunciamiento de Companys, fácilmente aplastado, y una insurrección socialista que en Asturias se convirtió en una pequeña guerra civil. Los republicanos de izquierda no participaron en el uno ni en la otra, pero ello no evitó que algunos de ellos fueran perseguidos por su supuesta complicidad. El propio Azaña fue detenido y las Cortes concedieron el suplicatorio para procesarle por la rebelión de Barcelona, pero el Tribunal Supremo no encontró fundamento suficiente para hacerlo y el 28 de diciembre fue puesto en libertad.

47 Francisco Largo Caballero, Escritos de la República, Madrid, Editorial Pablo Iglesias, 1985, p. 114-115.

48 AvLÉs, La izquierda..., p. 353-356. Otro análisis de la cuestión se encuentra en Juliá, Vida y tiempo..., p. 358-364.

49 «Discurso a los republicanos catalanes», 30-8-1934, en AzAÑa, Obras ..., V, p. 154-168.

50 Townson, La República ..., p. 304-311. 
«Los levantamientos de octubre de 1934 -ha escrito Townson- constituyeron un golpe devastador para las aspiraciones centristas del Partido Radical $\rangle^{51}$. Tras la derrota de las insurrecciones, la CEDA se sintió más legitimada en sus exigencias y algunos radicales, entre ellos Salazar Alonso, se sumaron a su aspiración de que se procediera al aplastamiento definitivo de las izquierdas. El periódico radical Renovación acusaba, por ejemplo, a los maestros de izquierdas de promover el adoctrinamiento revolucionario de sus alumnos, por lo que pedía una depuración de los docentes ${ }^{52}$. Otros radicales, como Ricardo Samper, defendían en cambio una política de reconciliación, mientras que Lerroux, como era habitual, se mostró ambiguo. Lo cierto es que el Gobierno cedió ante la presión del presidente Alcalá Zamora para que se conmutara la pena a unos oficiales que habían sido condenados a muerte por su participación en la rebelión de la Generalitat. Esto provocó indignación en la CEDA, que poco después demostró su poder cuando forzó la destitución de dos ministros radicales, Ricardo Samper y Diego Hidalgo, acusados de no haber sido suficientemente previsores respecto a la amenaza izquierdista ${ }^{53}$. Internamente escindido y sometido a la fuerte presión de la derecha accidentalista, de la que dependía su mayoría parlamentaria, el Partido Radical se veía abocado a un proceso de pérdida de identidad que terminó por conducirle a la irrelevancia política. Un proceso al que contribuyeron tanto la debilidad del líder radical como el excesivo intervencionismo del presidente de la República, que en su deseo de mantener el rumbo centrista de la República obstaculizó a Lerroux como antes había obstaculizado a Azaña.

Cuando en marzo de 1935 el propio Lerroux tomó la iniciativa para conmutar la pena a los dirigentes socialistas de la insurrección asturiana, los tres ministros de la CEDA dimitieron. El gobierno que Lerroux formó entonces sin participación cedista, sólo pudo mantenerse unas semanas, falto de mayoría parlamentaria. Las alternativas para los radicales eran de nuevo o la convocatoria de unas elecciones anticipadas, que temían, o la rendición ante las exigencias de la CEDA, por la que finalmente optó Lerroux cuando formó en mayo su quinto gobierno, en el que entraron cinco ministros de la CEDA y los radicales quedaron en minoría. La decepción que ello provocó en el ala izquierda del partido fue enorme y en la votación de confianza al nuevo gobierno se abstuvo la cuarta parte de los diputados radicales. El incumplimiento de la legislación laboral y la marginación de los militares más identificados con la República probaron la orientación netamente derechista del nuevo gobiemo. Los radicales se opusieron sin embargo a la radical reforma de la Constitución que pretendía la CEDA ${ }^{54}$.

El escándalo del estraperlo, motivado por una denuncia por corrupción remitida en mayo al presidente de la República por Daniel Strauss, un empresario que había tratado de obtener la licencia para un juego de azar mediante sobornos a políticos radicales, fue sólo la última gota que colmó el vaso del descrédito en que había caído Lerroux, quien se vio forzado a dimitir en septiembre. Hay indicios que Azaña y Prieto contribuyeron a que la denuncia se remitiera directamente a Alcalá Zamora y de que este la aprovechó para hundir a Lerroux, a quien la CEDA tampoco hizo nada por defender ${ }^{55}$. En las elecciones de febrero de 1936, presididas por un gobierno de centro impuesto por el presidente de la República,

\footnotetext{
51 Townson, La República..., p. 315.

52 Renovación, 10-11-1934.

53 Townson, La Republica..., p. 315-320.

54 Townson, La República..., p. 335-354.

55 Townson, La República..., p. 364-380.
} 
los radicales sólo obtuvieron ocho escaños, seis de ellos en coalición con la derecha, y el propio Lerroux quedó fuera de las Cortes ${ }^{56}$. Era el fin del lerrouxismo.

Para Azaña, en cambio, el año 1935 trajo consigo una enorme recuperación de su popularidad. Las víctimas de la represión se habían convertido en mártires para las izquierdas, como para la derecha lo eran las víctimas de la insurrección, incluidos los clérigos asesinados en Asturias, y en ese estado de ánimo, los casi tres meses de encarcelamiento de Azaña le convirtieron en el símbolo de la República izquierdista del primer bienio, que había que recuperar. Intelectuales de primera fila como Azorín, Américo Castro, León Felipe, Federico García Lorca, Juan Ramón Jiménez, Gregorio Marañón y Ramón del Valle Inclán figuraron entre los firmantes de una carta colectiva en favor del encarcelado Azaña, en noviembre de $1934^{57}$. Y una vez liberado, los llamados discursos en campo abierto que el líder de Izquierda Republicana pronunció en mayo en Valencia, en julio en Baracaldo y en octubre en el campo de Comillas, junto a Madrid, atrajeron a multitudes y demostraron la inmensa fuerza política que volvía a tener. Su discurso volvía a ser de centro-izquierda, sin las veleidades revolucionarias del año anterior. En Comillas defendió «una política estrictamente basada en la Constitución», la cual era «reformista en lo social, pero no socialista ni socializante» y llamó a «desterrar de todas partes el espíritu de venganza». Habia que «destruir absolutamente los privilegios de las clases adineradas», pero no con un espíritu de desquite, sino con el propósito de dar estabilidad a la sociedad española. En concreto llamó a que la coalición vencedora en las próximas elecciones restableciera y aplicara la legislación educativa y laboral del primer bienio, reorganizara la justicia, impulsara la reforma agraria, y adoptara una política fiscal y presupuestaria encaminada a «romper las grandes concentraciones de riqueza territorial y mobiliaria» ${ }^{58}$.

La aplicación de ese programa exigía, sin embargo, ganar las elecciones y ello implicaba un acuerdo electoral con un Partido Socialista escindido en dos alas, la encabezada por Prieto, que deseaba un nuevo acuerdo con los republicanos, y la encabezada por Caballero, que mantenía la línea estrictamente revolucionaria adoptada en 1934. Martínez Barrio, que coincidía con Azaña y Prieto en la necesidad de una coalición republicano-socialista, se sentía inquieto ante el peligro de verse arrastrados hacia una política demasiado izquierdista y, en un discurso de noviembre de 1935, advirtió que lo primero que necesitaba el país era consolidar la República y que cualquier otro salto hacia delante, impetuoso e imprudente, «aparejaría rápidamente la vuelta a una situación de tiranía y esclavitud ${ }^{59}$.

La derrota de Largo Caballero en el consejo nacional del PSOE, abrió la puerta a una nueva coalición republicano-socialista, esta vez con la incorporación de los comunistas como socios menores, que ha pasado a la historia con la denominación de Frente Popular. E1 16 de enero, se dio a conocer el manifiesto conjunto suscrito por las organizaciones que integraron el Frente Popular, cuyo programa quedó encomendado a un gobierno exclusivamente republicano, porque los socialistas no quisieron comprometerse de nuevo en la responsabilidad del Poder. Sólo un pequeño partido republicano, el encabezado por Felipe Sánchez Román, que había participado en la negociación del acuerdo, se negó a suscribir el manifiesto, debido a que no habían sido aceptadas dos exigencias que presentó: que los firmantes renunciaran expresamente a la táctica revolucionaria, incluso en su

56 Townson, La República ..., p. 395-396.

57 Azaña, Obras..., V, p. 197-198.

58 Azaña, Obras..., V, p. 441-464.

59 Diego Martínez Barrio, Memorias, p. 281-282. 
propaganda, y que pusieran fin a la militarización de sus juventudes ${ }^{60}$. En definitiva lo que Sánchez Román exigía era que la izquierda obrera se reintegrara a los cauces exclusivos de la legalidad, pero ello iba en contra de la estrategia revolucionaria caballerista, a pesar de lo cual Azaña y Martínez Barrio siguieron adelante con el Frente Popular.

En la primera vuelta, que fue decisiva en la gran mayoría de las circunscripciones, las candidaturas del Frente Popular recibieron aproximadamente los votos de un tercio del censo electoral, las de derechas otro tanto y las estrictamente de centro, auspiciadas por el Gobierno, las de un $5 \%$, mientras que algo más de la cuarta parte de los electores se abstuvieron $^{61}$. La ley electoral dio al Frente Popular una holgada mayoría absoluta, pero lo cierto es que el gobierno que Azaña formó en febrero de 1936 fue tan minoritario como el que Lerroux había formado en diciembre de 1933. Los dos partidos que lo integraban, Izquierda Republicana y Unión Republicana, sumaban tan sólo 125 escaños, así es que dependían del apoyo externo de los 99 diputados socialistas, de los 37 de la Esquerra y otros partidos catalanes, y de los 17 comunistas. Con el agravante de que la identificación de caballeristas y comunistas con la Constitución de 1931 no era mayor que la de Gil Robles y la CEDA.

Es probable que este factor fuera uno de los que Azaña tuviera en mente cuando, el 19 de febrero, anotó en su diario que siempre había temido volver al gobierno en malas condiciones y que aquellas no podían ser peores $^{62}$. A finales de marzo, escribió a su cuñado Cipriano Rivas Cherif que «lo del Frente Popular» andaba mediano, porque en los pueblos sus componentes no se entendían ${ }^{63}$. Pocos días antes, le había manifestado su «negra desesperación» por noticias como estas: «Hoy nos han quemado Yecla: 7 iglesias, 6 casas, todos los centros políticos de derecha, y el Registro de la propiedad ${ }^{64}$. El 10 de abril, concluyó, sin embargo, una carta a Rivas Cherif con un toque de optimismo, un broche de oro, porque tres días antes había logrado que las Cortes votaran la destitución de Alcalá Zamora, «que se disponía a jugarnos una mala partida» ${ }^{65}$. Ello le abrió la puerta a la presidencia de la República, que desde hacía tiempo ambicionaba: «ya desde el verano pasado, antes de formarse el Frente y de disolverse las Cortes, al ver la oleada del "azañismo", solía decir, y muchos lo oyeron, que yo no podía ser más que Presidente de la República, no sólo por mi comodidad, sino porque es el único modo de que el "azañismo" rinda lo que pueda dar de sí, en vez de estrellarlo en la Presidencia del Consejo ${ }^{66}$.

En realidad, ni Azaña en la presidencia de la República ni su correligionario Santiago Casares Quiroga en la del Gobierno rindieron demasiado: no pudieron frenar ni la creciente división del Frente Popular, ni el inquietante deterioro del orden público, ni el auge de las tendencias golpistas en las Fuerzas Armadas. Cabía entonces suponer que la coalición del azañismo con el caballerismo no iba a resultar más estable que la del lerrouxismo con la CEDA y que la fachada de unidad del Frente Popular no tardaría en quebrarse abiertamente, pero no podemos saber si ello habría llegado a acudir, porque el alzamiento militar de julio de 1936 cambió radicalmente el panorama político. Cuando, en septiembre de aquel año, ya en plena guerra civil, formó gobierno Largo Caballero, la izquierda republicana quedó

\footnotetext{
60 AvilÉs, La izquierda..., p. 382-384.

61 Avilés, La izquierda..., p. 385-389.

62 Azaña, Obras..., V, p. 628.

63 Carta a Rivas Cherif, 29-3-1936, en Azaña, Obras..., V, p. 645.

64 Carta a Rivas Cherif, 17-3-1936, en AzAÑA, Obras..., V, p. 640.

65 Carta a Rivas Cherif, 10-4-1936, en AzAÑa, Obras..., V, p. 647.

66 Carta a Rivas Cherif, 14-5-1936, en Azaña, Obras..., V, p. 651.
} 
reducida a una posición marginal. Era no sólo el fin del azañismo, sino de la República de 1931.

¿Hasta qué punto contribuyó la escisión del republicanismo al fracaso de la democracia republicana? Sin entrar en un ejercicio de historia contrafactual, me limitaré a unas breves reflexiones. En primer lugar, los efectos centrífugos de la competición electoral suelen hacer difícil que se impongan las tendencias estrictamente de centro, por lo que lo habitual en las democracias suele ser la alternancia de gobiernos de derecha e izquierda, de un sólo partido o de coalición, que sin embargo coinciden en los principios democráticos. En ese sentido si Azaña hubiera retenido a los socialistas en el terreno de la legalidad republicana y Lerroux hubiera atraido hacia ella a la CEDA, el resultado muy bien podría haber sido la consolidación de la democracia republicana y España podría haberse evitado la guerra civil. No fue así y los republicanos fueron en parte responsables de ello. Azaña y los suyos no prestaron suficiente atención a la deriva revolucionaria de los socialistas en 1933, negaron la legitimidad de las Cortes elegidas ese año y se embarcaron en la aventura del Frente Popular con unos aliados que no eran del todo leales a la República. Lerroux y los radicales, por su parte, cavaron un foso demasiado grande respecto a la izquierda republicana con su oposición frontal a Azaña en 1933 y no supieron darse cuenta de que se estaban poniendo en manos de una derecha que no sólo era accidentalista respecto a la República, sino que también lo era respecto a la democracia. 